\title{
Başarısız Bankart cerrahisine yaklaşım: Cerrahi teknikler ve klinik sonuçları
}

\author{
Approach to failed Bankart surgery: Surgical techniques and clinical results
}

\author{
Tahsin Beyzadeoğlü,2, Kerem Yıldırım \\ ${ }^{1}$ Beyzadeoğlu Klinik, İstanbul \\ ${ }^{2}$ Haliç Üniversitesi, Sağlık Bilimleri Fakültesi, İstanbul
}

\begin{abstract}
Omuz instabilitesinde birincil cerrahiden sonra gelişebilecek başarısızlığın en önemli nedeni instabilitenin nüksüdür. İnstabilitenin nüksü sonrası yapılacak revizyon cerrahisi ise birincil cerrahiden daha zordur ve daha az yüz güldürücü sonuçlara sahiptir. Bu durumda birincil tedavinin iflas nedenleriyle hastanın özellikleri belirlenmeli, yumuşak dokuların ve kemik yapının durumu uygun görüntüleme yöntemleriyle detaylıca ortaya konulmalı ve revizyon cerrahisi bu nedenlere yönelik olarak her hasta için özel olarak tasarlanmalıdır. Açık revizyon cerrahisi ile artroskopik revizyon cerrahisi arasında başarı ve sonuçlar açısından herhangi bir fark gösterilmiş olamamakla birlikte, temas sporları ve/veya fırlatmalı sporlar yapan hastalar ile askeri personel gibi diğer riskli gruplarda açık cerrahi daha ön planda düşünülmelidir. Ciddi glenoid ve/ veya humerus kemik kaybı durumlarında ise anterior glenoide yönelik kemik blok yöntemleri tercih edilmelidir. Bu derlemede, kanıta dayalı bir tedavi algoritması da dahil olmak üzere, başarısız Bankart onarımından sonra başarısızlığın etiyolojisi ve hastanın değerlendirilmesi ile farklı senaryolar için önerilen farklı tedavi yöntemleri üzerine odaklanılmıştır.
\end{abstract}

Anahtar sözcükler: Bankart; omuz instabilitesi; komplikasyon; revizyon

O muz instabilitesinin cerrahisi sonrası gelişebilecek ana komplikasyon, tekrarlayan instabilitedir. Revizyon instabilite cerrahisi genellikle zordur. Cerrahi sonrası tekrarlayan omuz instabilitesi olan hastalar; sadece başarısızlığı teşhis etmek için değil, aynı zamanda sonucu belirleyen altta yatan nedenleri de açıkça belirlemek ve başarılı bir tedavi stratejisi oluşturmak için detaylı olarak değerlendirilmelidir. En iyi tedavinin planlanabilmesi için dikkatli bir ameliyat
The most important reason for failure after shoulder instability surgery is the recurrence of instability. Revision surgery after recurrence of instability is more difficult than primary surgery and has less satisfactory results. In such a case, the reasons for the failure of the primary treatment and the characteristics of the patient should be determined, the condition of the soft tissues and bony structure should be revealed in detail with appropriate imaging methods, and revision surgery should be specially designed for each patient regarding these variables. Although no difference has been shown in terms of success and results between open revision surgery and arthroscopic revision surgery, open surgery should be considered more prominently in other risky groups such as patients participating in contact sports and/or overhead throwing sports and military personnel. In cases of serious glenoid and/or humeral bone loss, bone block methods for the anterior glenoid should be preferred. This review focuses on the etiology of failure, patient evaluation, and different treatment modalities recommended for different scenarios after failed Bankart repair, including an evidence-based treatment algorithm.

Key words: Bankart; shoulder instability; complication; revision

öncesi değerlendirme oldukça önemlidir. İnstabilitenin nedeni, atakların sayısı ve sıklığı, tekrarlama için gerekli travma şiddeti, ilk yaralanma anındaki kol pozisyonu ve semptomları tetikleyen kol pozisyonu hakkında detaylı bilgi edinilmelidir. ${ }^{[1]}$

\section{BAŞARISIZLIK NEDENLERi}

Cerrahi tedavinin iflas ettiği herhangi bir hasta, Tablo 1'deki gruplardan en az birine dâhil edilebilir. ${ }^{[1]}$

İletişim / Contact: Prof. Dr. Tahsin Beyzadeoğlu • E-posta / E-mail: tbeyzade@superonline.com

ORCID iD: Tahsin Beyzadeoğlu, 0000-0002-5836-4494 • Kerem Yıldırım, 0000-0003-1624-6438

Geliş / Received: 22 Aralık 2021 • Kabul / Accepted: 7 Şubat 2022 
Tablo 1. Omuz instabilitesi cerrahisi sonrası başarısızlı̆ı̆ın nedenleri[ ${ }^{[1]}$

\begin{tabular}{lc}
\hline Yanlış Tanı & Cerrahi ile ilişkili Etkenler \\
Cerrahi tedavinin endike olmadığı hastalar & Teknik hatalar \\
Ortaya konulmamış anatomik bozukluklar & Yetersiz tedavi \\
İnstabilitenin yönü & İmplant iflası: Çapa dikiş ya da greft \\
Hasta ile ilişkili Etkenler & Cerrahi Sonrası Yeni Travma \\
Yaş, cinsiyet & \\
Çıkık sayısı & Bilinmeyen Nedenler \\
Yapılan sporun türü (temaslı, yarışmacı, fırlatmalı) & \\
Eşlik eden ya da tetikleyen hastalıklar: Ehler-Danlos hastalığı, epilepsi vb. &
\end{tabular}

\section{Yanlış Tanı}

Başarısız cerrahi tedaviyi uygun şekilde ele alabilmek için, öncelikle cerrahinin endike olup olmadığını açıkça belirlemek önemlidir. İstemli glenohumeral çıkıklar genellikle genç erişkinlerde ortaya çıkma eğilimindedir, sıklıkla duygusal ve psikolojik problemlerle ilişkilidir. Çocuklukta görülen istemli subluksasyonda, konservatif tedaviyle olumlu uzun vadeli sonuçlar elde edilebildiği ve bu instabilitenin osteoartrit ile ilişkili olmadığı gösterilmiştir. ${ }^{[2]}$ Bu nedenle, bu zeminde tekrarlayan cerrahi sonrası instabilite, fizyoterapi ve rehabilitasyon ile konservatif olarak tedavi edilmelidir. ${ }^{[1]}$

En zor kararlardan biri de her bir hasta için hangi cerrahi tekniğin uygun olduğunun belirlenmesidir. Bu amaç doğrultusunda, instabilitenin yönünün yanı sıra, tekrarlamadan sorumlu diğer olası bozuklukların da ele alınması çok önemlidir. ${ }^{[1]}$

Zabinski ve ark., çok yönlü instabilite tanılı hastalarda rezidüel Bankart lezyonlarının daha az yaygın olduğunu ve hiperlaksitenin ise neredeyse her zaman bulunduğunu belirtmiş; revizyon omuz stabilizasyonunun tekrarlayan anterior instabilitesi olan hastalarda güvenilir bir prosedür olmasına karşın, çok yönlü instabilitesi olan hastalarda cerrahi başarısızlık ve sık tekrarlayan operasyonlar ile öngörülemez sonuçlara sahip olduğu sonucuna varmıştır. ${ }^{[3]}$

Klinik öykü ve titiz bir fizik muayene ile instabilitenin yönünün belirlenmesi, başarısızlığın olası nedenleri ve olası ilişkili lezyonlar hakkında bilgi sağlar. ${ }^{[4]}$ Fizik muayene her zaman ilgili omuz ile karşı taraf karşılaştırılarak yapılmalıdır. İnstabilitenin derecesi (çıkık, yarı çıkık veya endişe) de önemli bir bulgudur. ${ }^{[1]}$

Herhangi bir revizyon ameliyatından önce anestezi altında yapılacak muayene, hastanın endişesinden kaynaklanan klinik muayenenin kısıtlılığının üstesinden gelebileceğinden faydalı olabilir. Takılma veya kilitleme gibi mekanik semptomlar, yer değiştirmiş bir labral yırtık, eklem içi serbest bir cisim veya angaje olan büyük bir kemik defektine işaret edebilir. Azalmış eklem hareket açıklığı (EHA), ameliyat sonrası sertlik, kondroliz, glenohumeral osteoartrit veya kapsülolabral ligamentöz kompleksin aşırı gerginliğine bağlı olabilir (Şekil 1). Daha önce açık cerrahi geçirmiş olan hastalarda özellikle subskapularis kas fonksiyonuna yönelik dikkatli bir rotator manşet muayenesi yapılmalıdır. Sachs ve ark., açık Bankart onarımı yapılan hastaların \%23'ünün yetersiz subskapularis fonksiyonuna sahip olduğunu ve revizyon cerrahisinden sonra hastaların sadece \%57'sinde iyi veya mükemmel sonuçlar elde edilebildiğini bildirmişlerdir. ${ }^{[5]}$

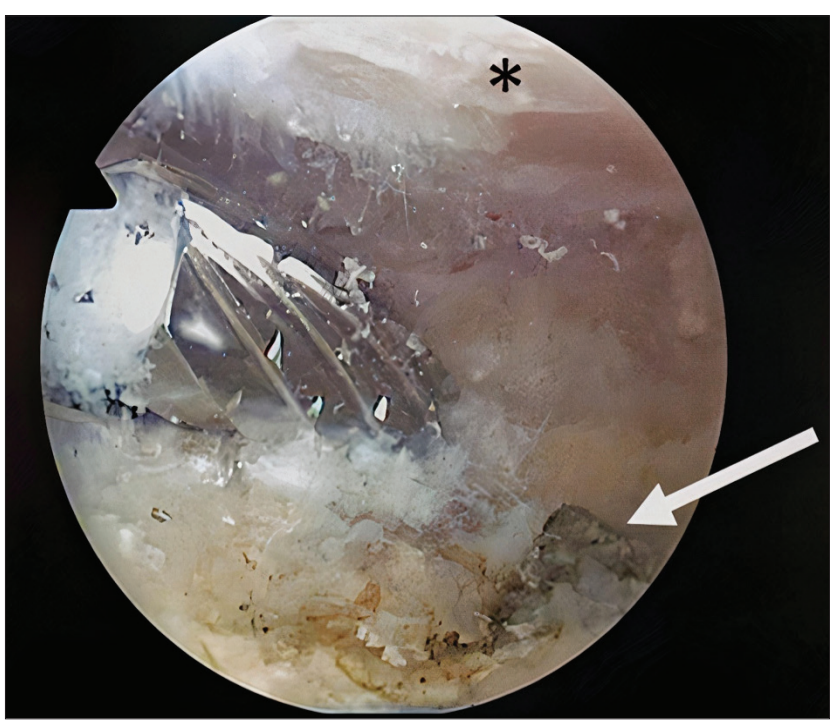

Şekil 1. Omuz instabilitesi cerrahisi sonrasın omuzda ağrı ve hareket kısıtlılığı gelişen hastada eklem içine uzanan metal çapa dikiş (ok) ve karşısındaki humerus başı eklem yüzeyinde oluşturmuş olduğu kıkırdak hasarının (yıldız) artroskopik görünümü. 
Düz grafiler, başvurulacak ilk basamak görüntüleme yöntemleridir ve supraspinatus outlet, gerçek antero-posterior ve aksiller görüntüleri de içermelidirler. Aksiller görüntü ile humerus başının anterior ya da posteriora subluksasyonu veya kemik greftinin iyileşme durumu değerlendirilebilir. Eklem içi kontrast maddeli manyetik rezonans görüntüleme (MRG ve MR artrografi, MRA), omuz instabilitesi için hem ameliyat öncesi hem de ameliyat sonrası takipte kullanılabilir ve kapsülolabral-ligamentöz kompleksin iyi bir değerlendirmesini sağlayarak ameliyat sonrası nüks veya komplikasyonları değerlendirebilir. Manyenik rezonans artrografi, yumuşak doku yaralanmalarını, rotator manşet yırtıklarını, glenohumeral ligamentin humeral avulsiyonu (HAGL) lezyonlarını, kapsülolabral lezyonları, kondral lezyonları ve eklem kapsülünün gevşekliğini veya rüptürünü standart MRG'den daha iyi gösterir. ${ }^{[6]}$ Abduksiyon ve dış rotasyon (ABER) pozisyonunda çekilen MRA, travmatik olmayan çok yönlü instabilitesi olan hastaları belirlemek noktasında yardımcı olabilir. Bilgisayarlı tomografi (BT) ise, kemik yapının değerlendirilmesi için ve direkt grafilerin implant pozisyonu hakkında yeterli bilgi vermediği durumlarda kullanılabilir. ${ }^{[1]}$

\section{Hasta ile ilişkili Etkenler}

Cerrahi stabilizasyonu takiben gelişen nüks riskini arttırabilecek prognostik etkenleri belirlemeye yönelik birçok çalışma yapılmıştır. Bu çalışmaların hemen hepsinde kemik defektlerinin varlığına ek olarak genç yaş ve riskli fiziksel aktivitelere katılım majör prognostik faktörler olarak belirlenmiştir. ${ }^{[7,8]}$ ilk çıkıktaki genç yaş ve erkek cinsiyetin, ilk çıkıktan sonra \%80'e yaklaşan yüksek instabilite nüks riski ile güçlü bir ilişki sergilediği gösterilmiştir. ${ }^{[7-9]}$ Bir başka çalışmada ise, 20 yaşından genç hastalarda ameliyat sonrası çıkık riski \%12,6 ve birincil stabilizasyondan sonra revizyon oranı \%7,7 olarak bulunurken, 29 yaşından büyük hastalarda bu risklerin sırasıyla $\% 5,5$ ve $\% 2,8$ olduğu tespit edilmiştir. ${ }^{[2]}$ Ayrıca, literatürde artroskopik onarım sonrası tekrarlayan çıkığı olan hastaların \%90'ının erkek olduğu da bildirilmiştir. ${ }^{[4,10]}$

Stabilizasyondan önceki çıkık sayısı ve önceki ameliyatların sayısı, ameliyat sonrası başarı ile negatif ilişkilidir. ${ }^{[11]}$ Wasserstein ve ark., üç veya daha fazla çıkığı olan hastaların revizyon cerrahisi riskinin iki kat ve yeniden çıkık riskinin on kat daha fazla olduğunu göstermişlerdir. [9] Birden fazla stabilizasyon cerrahisi geçirmiş olan hastaların, daha düşük fonksiyonel sonuçlar ve hasta memnuniyeti sergiledikleri de bilinmektedir. ${ }^{[12]}$

Cho ve ark. ile Rhee ve ark., artroskopik Bankart onarımından sonra aktif sporcularda $(\% 17,2)$ yüksek instabilite nüks oranı bildirmişlerdir. Temaslı sporlar yapan hastalarda daha da yüksek oranlar bildirilmiştir $(\% 25-28) \cdot{ }^{[13,14]}$

Balg ve ark., artroskopik Bankart onarımının başarısını öngörebilmek için instabilite şiddeti indeks skorunu (ISIS) geliştirmişlerdir. ${ }^{[15]}$ instabilite şiddeti indeks skoru 0 ile 10 arasında değişmektedir ve daha yüksek skorlar, stabilizasyondan sonra daha yüksek bir instabilite nüks riskini öngörmektedir. Daha yüksek bir nüks oranını öngörebilen belirli risk faktörleri göz önünde bulundurulur. Ameliyat sırasında hastanın yaşı (20'nin üzerinde veya altında), ameliyat öncesi sporun seviyesi ve türü, hiperlaksite ve direkt grafilerde tespit edilen kemik kaybı bu risk faktörlerindendir.

Epileptik nöbetler omuz çıkığı ve instabiliteye neden olabilir, ancak bu hastalar karakteristik bir instabilite paternini takip ederler. Bühler ve Gerber, primer onarımdan sonra posterior instabiliteye kıyasla anterior instabilite için daha yüksek bir nüks oranı bildirmişler (\%47’ye karşı \%12) ve söz konusu nükslerin çoğunun epilepsi hastalığının yetersiz kontrolü ile ilişkili olduğunu belirtmişlerdir. ${ }^{[16]}$ Bir başka çalışmada ise kemik kaybı ve cerrahi sonrası devam eden epileptik nöbetler tekrarlayan instabilite için temel faktörler olarak tanımlanmışlardır. Epilepsinin medikal kontrolü ve kemik blok prosedürleri, daha düşük nüks oranları ile ilişkilendirilmiştir. ${ }^{[17]}$

\section{Cerrahi ile ilişkili Etkenler}

\section{Yetersiz tedavi: Anatomik bozukluklar ve stabilizasyon tekniği}

Omuz stabilizasyon cerrahisi hastaya ve omuzda bulunan spesifik bozukluklara göre tasarlanmalıdır. Rowe ve ark., cerrahi sonrası omuz instabilitesi gelişen hastaların \%85'inden fazlasında yeterince ele alınmayan ve nüksü açıklayan bir bozukluğun tanımlanabileceğini göstermişlerdir. ${ }^{[18]}$ Dahası, Meehan ve Petersen, benzer bir çalışmada vakaların neredeyse yarısında birden fazla tanı konulamamış lezyon olduğunu kanıtlamışlardır. [19] Omuz instabilite cerrahisi sonrasında başarısızlığına yol açabilecek en yaygın bozukluklar, onarılmamış veya medial olarak onarılmış Bankart lezyonu, zayıf kapsülolabral doku veya hiperlaksite ile ihmal edilmiş glenoid veya humerus kemik defektleridir. ${ }^{[3,18-20]}$

Çoklu rekürrens epizodlarından sonra uygulanan Bankart onarımı sırasında yapılan en yaygın hata, yetersiz labral sıyırma ve bunu takiben zaten fazla medialde iyileşmiş olan labrumun anatomik olarak aynı yere yeniden tespitidir. ${ }^{[1]}$ Anterior labroligamentous periosteal sleeve avulsion (ALPSA) lezyonları, nüks için ayrı bir risk etkeni olarak tanımlanmıştır. ${ }^{[11,21]}$ Glenohumeral ligamen- 
tin humeral avulsiyonu lezyonlarının önemsenmemesi de ameliyat sonrası rezidüel instabiliteden sorumludur. Bankart lezyonu ve çok yönlü instabilitenin bulunmadığı, ilk kez gelişen omuz çıkığı vakalarında HAGL (humeral avulsion of the glenohumeral ligament) lezyonu insidansının daha yüksek olduğu gösterilmiştir. ${ }^{[22]}$

Yanlış yerleşimli çapa dikişler de instabilite nüksü ile ilişkilendirilmiştir. ${ }^{[23]}$ Primer artroskopik Bankart onarımı için kullanılan çapa dikişlerin sayısı da nüks oranında önemli bir rol oynar ve anterior omuz instabilitesi vakalarında genellikle üç veya daha fazla çapa dikiş ile tespit önerilir. ${ }^{[11,24,25]}$ Kullanılan çapa dikişlerin materyali konusunda metal ve biyo-emilir implantlar arasında nüks riski açısından bir fark olmadığı bilinmekle birlikte, dügümsüz çapa dikişlerin düğümlülere oranla daha yüksek nüks riski ile ilişkili olduğu bildirilmiştir. ${ }^{[26,27]}$

Cerrahi sırasında en sık yapılan hatalardan biri, artroskopik onarım sırasında kapsüler gevşekliğin fark edilememesi ve gerekli girişimin yapılmamasıdır. ${ }^{[3,18-20]}$

Tekrarlayan omuz çıkıklarından sonra anterior kapsül dokusu gerilebilir ve bunun sonucu olarak bol kalabilir. [12,19] Bigliani ve ark., ön kapsülün gerilmesinin labral yaralanma ile veya labral yaralanmasız meydana gelebileceğini göstermiştir. ${ }^{[28]}$ Rowe ve ark. ise cerrahi onarımdan sonra tekrarlayan çıkıkları olan hastaların \%83'ünde belirgin kapsüler gevşeklik olduğunu bildirmişlerdir. ${ }^{[18]}$

Anterior glenoid kemik defekti olan hastalarda instabilitenin tekrarlaması riski daha yüksektir. ${ }^{[7]} \mathrm{Hem}$ glenoid hem de humerus başı kemik defektlerinin ölçülmesinde BT ideal yöntem olarak kabul edilmektedir. \%20'nin üzerindeki bir glenoid kemik defekti ile Bankart onarımından sonra yüksek nüks oranları arasında güçlü bir ilişki bulunduğu bilinmekle birlikte ${ }^{[25,29]}$; Calvo ve ark., eklem yüzeyinin \%15'ini içeren bir glenoid kemik defektinin bile daha yüksek cerrahi başarısızlık riskine neden olduğunu göstermişlerdir. ${ }^{[30]}$ Yamamoto ve ark. bipolar kemik lezyonunun anlamlı olup olmadığını belirleyen "glenoid iz (glenoid track)" kavramını geliştirmişlerdir. ${ }^{[31]}$ Glenoid iz konsepti, cerraha lezyonların boyutu ve morfolojisine dayalı olarak angajmanı tahmin etme imkânı sunar. ${ }^{[32]}$ Güncel klinik literatür, bipolar kemik kaybı olan omuzlarda izole Bankart onarımının başarısızlığını öngörmede glenoid iz kavramına dayanan on-track ve off-track modelini desteklemektedir. ${ }^{[33]}$

Kemik defektlerini gidermek için kemik greft ile güçlendirme teknikleri tercih edilir ve Latarjet prosedürü bu gibi durumlarda altın standart olarak kabul edilir. ${ }^{[34]}$ Açık Bristow prosedürü uygulanan omuz stabilizasyonundan sonra ağııı instabilitesi olan hastaların \%59'unda nükslerin kapsülün bolluğuna bağlı olduğu gösterilmiştir.
${ }^{[35]}$ Ayrıca, daha önce kemik blok prosedürleri ile tedavi edilen hastalarda tekrarlayan instabilitenin artroskopik revizyonunda labral defektler ve kapsüler uzamaların varlığı ile karşılaşılmıştır. ${ }^{[36]}$ Bu nedenle artroskopik muayenenin bu bozuklukların belirlenmesinde son derece önemli olduğu düşünülmektedir. Latarjet sonrası gelişen instabiliteyi, korakoid greftin kötü yerleşimi, kötü kaynaması veya kaynamaması gibi komplikasyonlara bağlayan yazarlar da vardır. ${ }^{[37]}$

Cerrahi stabilizasyonun ardından gelişen nükste belirli Hill-Sachs defektlerinin de rol oynadığı bilinmektedir. [24] Off-track Hill-Sachs lezyonları, artroskopik Bankart onarımı sonrası instabilitenin tekrarlamasında, on-track defektlere oranla, revizyon cerrahisi ihtiyacı açısından önemli bir risk oluştururlar. ${ }^{[38]}$

Literatürdeki karşılaştırmalı çalışmalara dayanarak, açık veya artroskopik stabilizasyonun nüks açısından üstünlüğüne dair herhangi bir kanıt bulunmadığı söylenebilir. ${ }^{[1]}$

\section{Cerrahi Sonrası Yeni Travma}

Cerrahi sonrası geçirilen travmatik yaralanmalar, nüksün en büyük nedenlerinden biridir. Etkilenenlerin çoğu, ilk yaralanmaları genellikle atletik faaliyetler nedeniyle olan genç hastalar olduğundan, temaslı sporlara veya baş üstü fırlatma sporlarına dönüş, bu popülasyonu yeniden yaralanmaya yatkın hale getirir. illk omuz çıkıklarının $\% 85$ 'inin ve cerrahi stabilizasyon sonrası gelişen nüks çıkıkların \%59'unun travmatik olduğu gösterilmiştir. ${ }^{[20]}$

Çapa dikişlerin yerleşiminin kemikte osteolize yol açabileceği ve/veya glenoid kenarında stres noktaları oluşturabileceği, bu durumda da düşük enerjili travmalar sonucunda çapa dikişlerin yerleşim yerlerinden geçen bir kırık hattı ile karakterize olan glenoid kenar kırığı "posta pulu kırığı (postage stamp fracture)" gelişebileceği de bildirilmiştir (Şekil 2 ve Şekil 3). ${ }^{\left[{ }^{[3]}\right.}$ Bankart onarımı sonrası farklı çalışmalarda belirtilmiş olan risk faktörleri Tablo 2'de gösterilmiştir. ${ }^{[40]}$

\section{HASTANIN DEĞERLENDIRILMESi}

Başarısız omuz instabilitesi cerrahisi sonrasında tedavinin planlanması aşamasında hastanın detaylı bir fizik muayenesi yapıldıktan sonra klinik öyküsü ve görüntüleme sonuçları dikkatlice incelenmelidir. Önceki ameliyatlara ait ameliyat notları ve hastanın ameliyat sonrası almış olduğu fizyoterapi hakkında da bilgi sahibi olunmaııdır. Başarısız artroskopik Bankart onarımı durumunda, yumuşak dokuların ve glenoid ve/veya humerus başındaki kemik kaybının doğru bir şekilde değerlendirilmesi de elzemdir. 


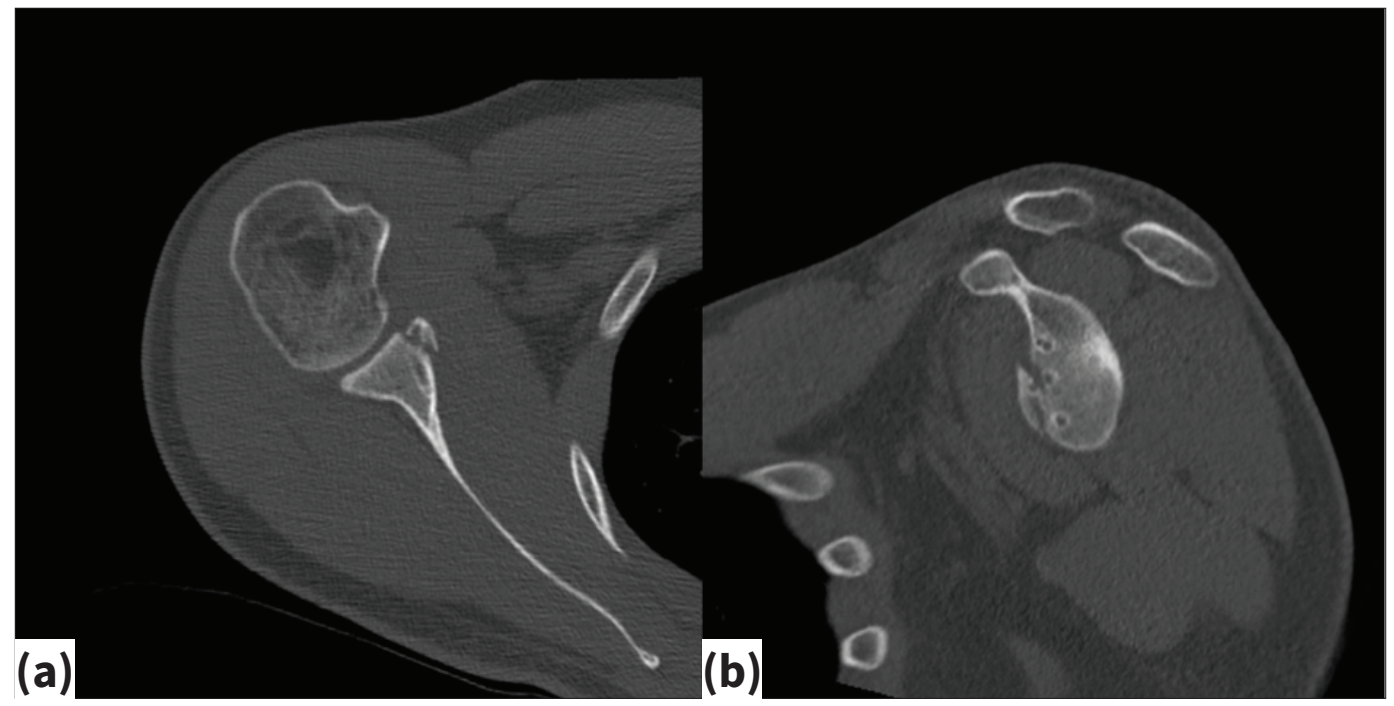

Şekil 2.a,b. 29 yaşında erkek hastada çapa dikişler ile gerçekleştirilen artroskopik Bankart onarımından dokuz yıl sonra bisikletten düşme sonucu gelişen "posta pulu" kırığını gösteren transvers (a) ve sagittal (b) BT kesitleri.

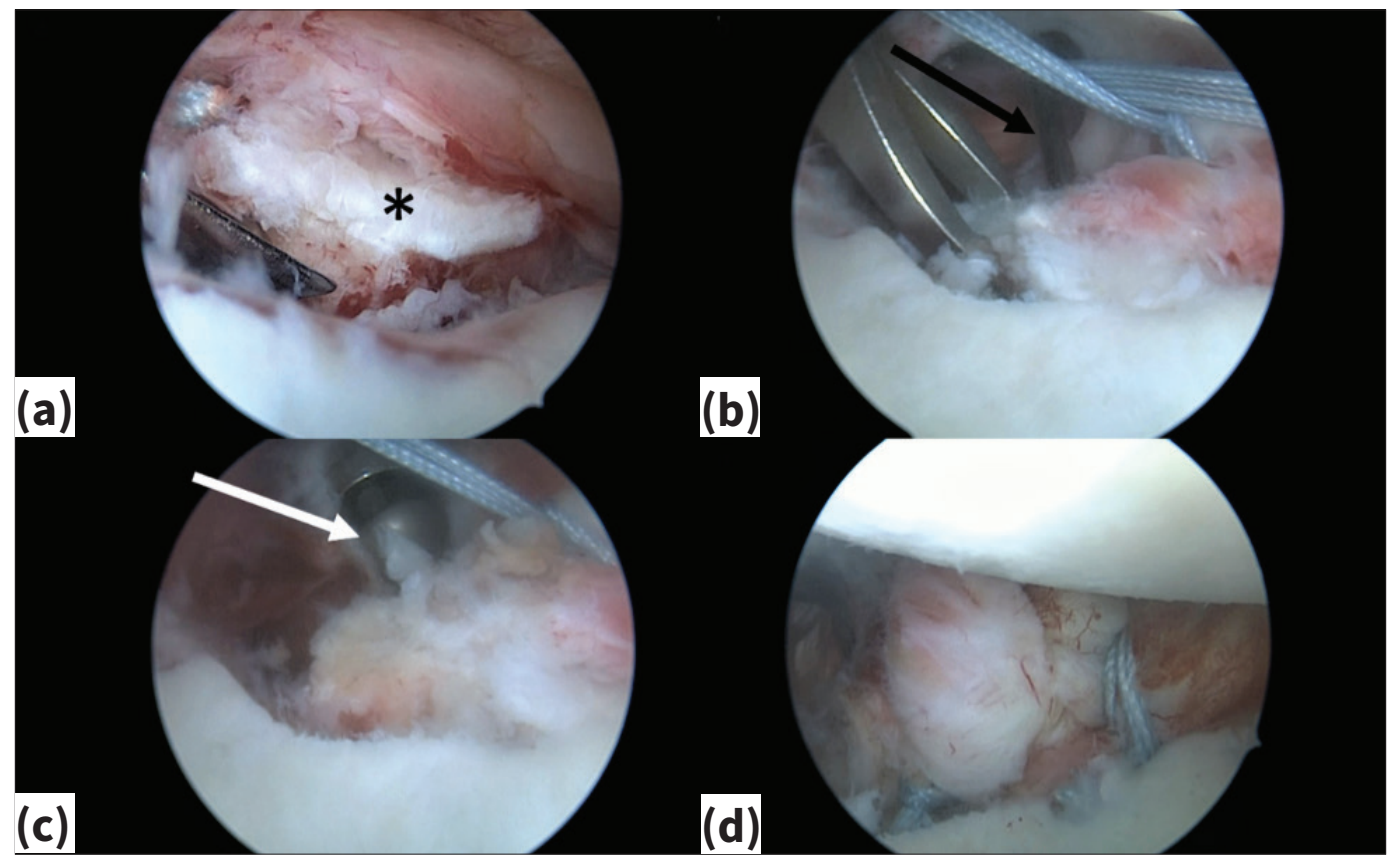

Şekil 3.a-d. Şekil 2'de gösterilmiş olan kırığın artroskopik görüntüleme altında perkütan vidalama ile tespitinin artroskopik görüntüleri; anterior glenoiddeki deplase kırık fragmanı (yıldız) (a), redükte edilen fragmanın Kirschner teli (siyah ok) ile geçici tespiti (b), kırık fragmanının kanüle vida (beyaz ok) ile kesin tespiti (c), kırık fragmanının redüksiyonu ve tespitinin ardından yapılan Bankart onarımı sonrası görünüm (d).

\section{TEDAVI SEÇENEKLERi}

\section{Cerrahi Dışı Tedavi}

Başarısız Bankart onarımından sonra, cerrahi olmayan tedavinin çağdaş klinik uygulamada sınırlı bir rolü vardır ve genellikle yapısal hiperlaksitesi veya kollajen bozuklukları, istemli çıkıkları ya da ilerleyici instabilite ile ilişkili artropatisi olan veya ameliyatı reddeden kişiler için konservatif tedavi tercih edilebilir. Bu hastalarda, öznel instabilite ve endişe duygularını giderebilmek için aktivite modifikasyonlarına, rotator manşet güçlendirmesine ve skapula çevresi kontrole ağırlık verilmelidir. ${ }^{[41]}$ 
Tablo 2. Artroskopik Bankart onarımı sonrası nüks için farklı çalışmalarda belirtilmiş olan risk faktörleri[40]

\begin{tabular}{ll}
\hline Yaş $\leq 20$ & ALPSA lezyonu \\
Yaş $\leq 30$ & Ameliyat öncesi çıkık sayısı > 1 \\
Yarışmacı sporlara katılım & ilk çıkıktan sonra ameliyata kadar geçen süre $>6$ ay \\
Hill-Sachs lezyonu & ISIS $>3$ \\
Off-track Hill-Sachs lezyonu & ISIS $>6$ \\
Glenoid kemik kaybı &
\end{tabular}

ISIS: İnstabilite şiddeti indeks skoru, ALPSA: Anterior labroligamentous periosteal sleeve avulsion.

\section{Cerrahi Tedavi}

Başarısız Bankart cerrahisinden sonra tekrarlayan anterior omuz instabilitesinin cerrahi tedavisine yönelik seçenekler, revizyon artroskopik Bankart onarımı, kapsüler kaydırma ile açık Bankart onarımı, anterior-inferior glenoid kemik bloğu rekonstrüksiyonu (Latarjet prosedürü) ve/veya posterolateral humerus başı rekonstrüksiyonu olarak sıralanabilir.

\section{Artroskopik revizyon}

Artroskopik revizyon pek çok avantaj sağlar ve tekrarlayan omuz travması geçiren, makul bir yumuşak doku kalitesine sahip hastalarda tercih edilebilir. Bu yöntem aynı zamanda, posterior-inferior bir labral yırtık uzantısı veya HAGL gibi eşlik eden labral, kondral veya kapsüler patolojilerin ayrıntılı olarak görüntülenmesini ve tedavisine imkân verirken, önceki ameliyatta uygulanmış olan implantları veya dikiş materyalini çıkarmayı da mümkün kılabilir. ${ }^{[40]}$

Remplisaj yöntemi ise, infraspinatusun angaje olan bir Hill-Sachs lezyonuna kapsülotenodezisini içerir. Bu yöntem, humerus başı angajmanını belirgin şekilde azaltabilir ve revizyon anterior stabilizasyonun yanında artroskopik olarak gerçekleştirilen ve anatomik olmayan rekonstrüktif bir yardımcı yöntem olarak kullanılabilir. ${ }^{[40]}$

Artroskopik revizyon, açık cerrahi prosedürüne göre daha az cerrahi saha morbiditesine neden olur, kısmi bir subskapularis kaldırma işlemi intiyacını ortadan kaldırır ve sıklıkla açık revizyon sonrası görülen yumuşak doku yapışıklıklarını sınırlandıır. Yayınlanmış olan olgu serilerinde, çağdaş çapa dikişler kullanılarak yapılan revizyon artroskopik labral onarımdan sonra \%6 ile \%27 arasında geniş bir aralıkta değişen başarısızlık insidansları bildirilmektedir. ${ }^{[42]}$ Bununla birlikte, McCabe ve ark., orta derecede humerus kemik kaybı olan ve ardından remplisajlı revizyon artroskopik onarım yapılan hastaların, primer stabilizasyon cerrahisi yapılan hastalara kıyasla belirgin düzeyde daha yüksek başarısızlık oranı (\%36) gösterdiğini ve bu nedenle artroskopik girişimlerin reviz- yon cerrahisindeki potansiyel rolünün sınırlı olabileceği görüşünü ortaya koymuştur. ${ }^{[43]} \mathrm{Az}$ miktarda kemik kaybı olan, kanıtlanabilir teknik hatalar belirlenebilen, yüksek enerjili travmatik instabilite nüksü gelişen veya daha düşük fonksiyonel beklentileri olan hastalarda revizyon artroskopik onarım; üçten fazla tespit noktası, yeterince inferiora yerleştirilmiş çapa dikişler (örn., saat 5'ten 7'ye kadar) ve ek posterior-inferior veya transubskapularis portallar ile yapılacak şekilde tercih edilebilir. ${ }^{[4]}$

\section{Açık revizyon}

Bu seçenek, tek yönlü instabilitesi, kritik düzeyin altında glenoid kemik kaybı ve/veya kapsül gevşekliği olan yüksek riskli hastalarda (örn., temaslı sporlar veya baş üzeri fırlatma sporları yapan atletler ve askeri personel) tercih edilebilir. Orijinal prosedürün dezavantajları arasında; atrofiden kaynaklanan subskapularis yetmezliği, yağlı infiltrasyon ve kısmi veya tam tenotomiden kaynaklanan dinamik anterior kısıtlamanın kaybı sıralanabilir. Bununla birlikte, bu riskler, artroskopik tekniklere kıyasla omuzun rotasyonel gücü üzerinde kayda değer hiçbir olumsuz etki göstermeyen, modifiye subskapularis-splitting yaklaşımının kullanılmasıyla önlenebilir ${ }^{[45]}$ Açık yaklaşımın yararlarI, EHA boyunca kapsül gerginliğinin derecesinin ayarlanabilmesi ve ön-arka translasyonu daha da azaltmak için isteğe bağlı olarak rotator intervalin kapatılmasının mümkün olmasıdır. Ayrıca, yeterli doku kalitesi mevcutsa, çapa dikişler ile gerçekleştirilecek tespit ile ön kapsülolabral restorasyon bir takoz etkisi de oluşturulabilir. Bunlara ek olarak, belirli yaralanmaların, özellikle HAGL lezyonlarının, deneyimli ellerde bile standart artroskopik tekniklerle tedavisi zor olabilir. Bu nedenle, inferior glenohumeral ligament (IGHL) kompleksine erişim ve çapa dikişler ile onarım sağlayan, inferiorda $L$ şeklinde bir subskapularis ayırmayl ${ }^{[46]}$ veya subskapularis koruyucu tekniğ ${ }^{[47]}$ içeren mini açık bir yaklaşım da tanımlanmıştır. Mevcut literatürde açık onarım sonrası düşük nüks oranları $(\% 0-11,5)$ bildirilmiştir. ${ }^{[48-50]}$ 


\section{Anterior glenoidin kemik blok ile stabilizasyonu}

Anterior glenoid kemik blok prosedürleri, özellikle Latarjet prosedürü veya korakoid transferi, başarısız primer stabilizasyon cerrahisinden sonra yapılan revizyon artroskopik ve açık Bankart prosedürlerinin yerini almaya başlamıştır. Artroskopik olarak gerçekleştirilebilen tekniklerin de geliştirilmiş olmasına ve şu anda belirli merkezlerde kullanılmasına karşın, açık Latarjet prosedürü hala daha yaygın olarak kullanılmaktadır. Bu işlem; mevcut glenoid temas yüzey alanını genişleten kemik rekonstrüksiyonu, abduksiyona ve dış rotasyona getirilmiş olan konjoint tendonun askı benzeri bir kısıtlama etkisi ve kapsül onarımı/güçlendirmesini içeren üçlü etkinin sağlanmasını mümkün kılar.

Farklı cerrahi teknikler tarif edilmiştir ve bu teknikler, kapsüle yapılacak müdahaleye, greftin eklem içi veya eklem dışına yerleştirilmesine ve korakoid çıkıntı (proses) tespitinin yönüne göre farklılıklar gösterirler. ${ }^{[40]}$ Geleneksel teknik, eklem içi greft yerleşimi için korakoakromiyal ligamanın kapsüler onarımını ve yeni eklem yüzeyi olarak korakoidin lateral kenarının kullanımını içerir. Bunun aksine, Burkhart ve ark., daha büyük bir yüzey alanını yeniden oluşturmak için tercihen inferior yüzeyin glenoid yüzeye yerleştirildiği uyumlu ark tekniğini savunmuşlardır. ${ }^{[51]}$ Bu oryantasyon, glenoidin eklem arkını genişletebilse de daha ince olan korakoid morfolojisi nedeniyle vida tespiti sırasında hata yapılması ve greft kırılma riski veya vidanın daha az kemik dokuda tespit sağlaması ve greft iyileşmesi için daha küçük bir yüzey alanı bulunması risklerini de beraberinde getirmektedir. ${ }^{[52]}$ Klinik olarak, Latarjet prosedürü ile revizyon yapılan olgularda daha düşük nüks oranları (\%0-14,3) bildirilmiştir. ${ }^{[53]}$

Ancak bu teknikler ile \%25-30'a kadar ulaşan sekonder komplikasyon oranları bildirilmiştir. Özellikle de aksiller ya da muskulokutanöz sinir yaralanmaları ${ }^{[54]}$ gelişebilmekte ve greft osteolizisi ameliyat öncesi glenoid kemik kaybının derecesine bağlı olarak \%39,6-65,1 seviyelerine kadar varabilmektedir. ${ }^{[55]}$ Alternatif olarak, Provencher ve ark., özellikle $\% 30$ veya daha fazlasına yaklaşan daha büyük glenoid kemik kayıplarında, taze distal tibial osteokondral allogreft kullanımını önermiştir. ${ }^{[56]}$ Bu greft kaynağı, benzer bir subskapularis-splitting yaklaşımıyla açık veya artroskopik olarak doğal eklem kıkırdağını restore etmek için tek seçenektir. Ancak bu kaynağın; genel maliyet, greft ulaşılabilirliği, biyolojik bütünleşmedeki potansiyel sınırlar ve hastalık bulaşma riski ile ilgili hususlar açısından diğer greft kaynaklarıyla karşılaştırılması gerekir. Benzer şekilde, daha büyük derecelerde kemik kayıpları için otojen trikortikal iliak kanat grefti kullanılan Eden-Hybinette prosedürü, tarif edilmiş olan hem açık hem de artroskopik tekniklerle birlikte uygulanabilir. ${ }^{[57]}$ Bu yöntem, iliumun iç yüzeyinin kullanımıyla uygun bir uyum sunsa da verici saha morbiditesi, hastaların \%25'inden fazlasında gelişen kalıcı ağrı veya semptomlar açısından en dikkate değer endişe olmaya devam etmektedir. ${ }^{[53]}$ Ayrıca bir askı etkisi ya da provokatif baş üzeri hareketler sırasında dinamik bir kısıtlayıcı etki de sağlanamamaktadır. ${ }^{[40]}$

Kritik düzeyin altında glenoid kemik kaybı bulunan olgularda angaje olan Hill-Sachs veya off-track lezyonların tedavisinde, instabilite tekrarı riskini azaltmak için mevcut artroskopik veya açık tedavilere remplisaj eklenebilir. Ancak mevcut literatür, anatomik olmayan bu tedavinin EHA'da kayda değer kayıplara neden olabildiğini göstermektedir. ${ }^{[58]}$

Revizyon veya kurtarma prosedürleri için daha çağdaş anatomik rekonstrüktif seçenekler olarak taze femur veya humerus başı osteokondral allogreftleri, fokal humerus başı yüzey yenileme artroplastisi veya ileri

Tablo 3. Farklı revizyon teknikleri sonucunda bildirilen başarısızlık oranları

\begin{tabular}{|c|c|c|c|}
\hline Artroskopik revizyon (Çapa dikişler ile labrum onarımı) & Nüks Oranı & Açık revizyon ve kapsüler kaydırma & Nüks oranı \\
\hline Patel ve ark. $(2008)^{[60]}$ & $\% 10$ & Neviaser ve ark. $(2015)^{[48]}$ & $\% 0$ \\
\hline Franceschi ve ark. $(2008)^{[61]}$ & $\% 10$ & & \\
\hline Bartl ve ark. $(2011)^{[44]}$ & $\% 10,7$ & Schmid ve ark. $(2012)^{[65]}$ & $\% 4,1$ \\
\hline Krueger ve ark. $(2011)^{[63]}$ & $\% 10$ & Bonnaviale ve ark. $(2013)^{[66]}$ & $\% 0$ \\
\hline Neri ve ark. $(2011)^{[64]}$ & $\% 27,2$ & Flinkkilä ve ark. $(2015)^{[67]}$ & $\% 14,3$ \\
\hline
\end{tabular}




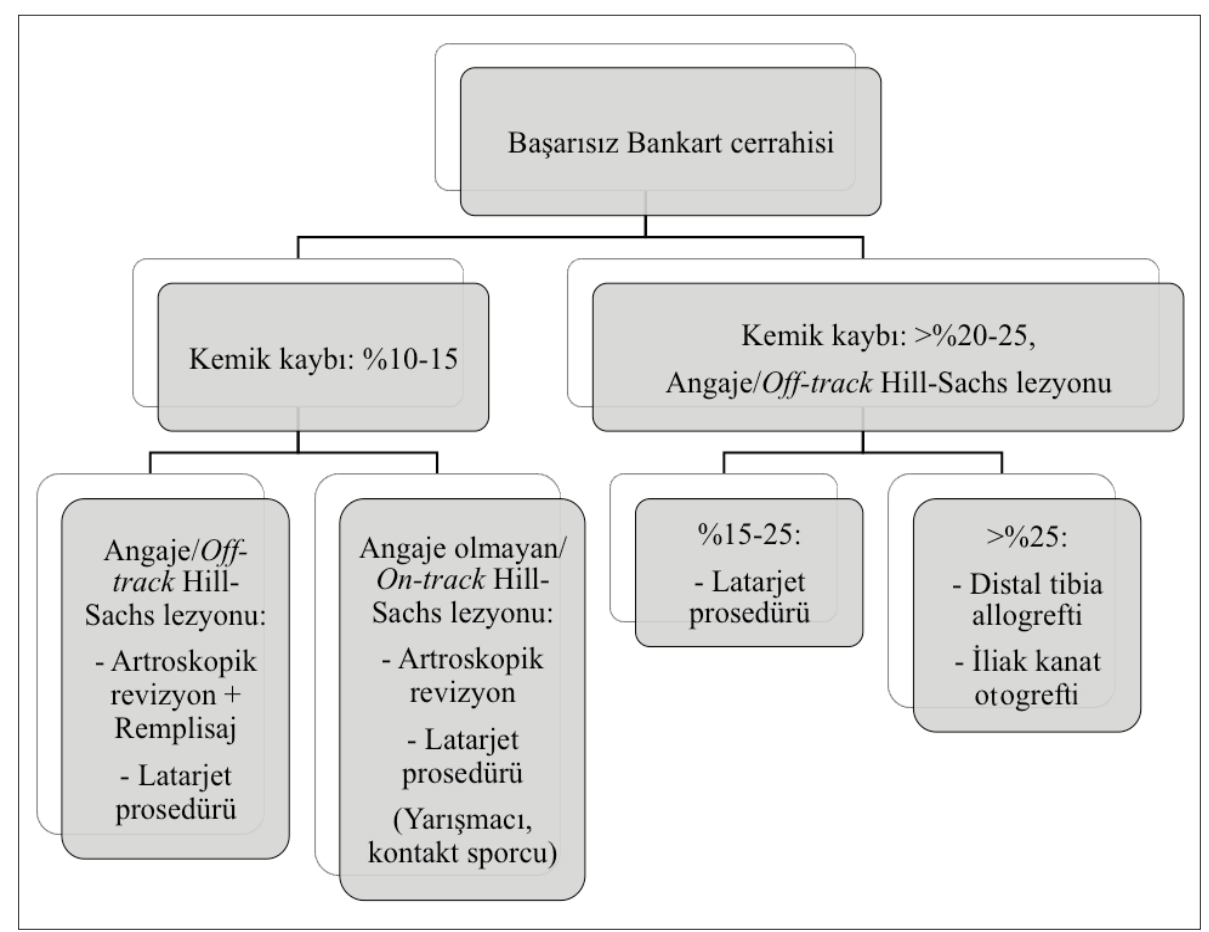

Tablo 4. Başarısız Bankart cerrahisi sonrası önerilen tedavi algoritması ${ }^{[41]}$

dejenere olgularda hemiartroplasti kullanımı da araştırılmıştır. Umut verici olmalarına rağmen, bu teknikler hakkında yeteri kadar yüksek kaliteli prospektif klinik veri bulunmamaktadır ve optimal endikasyonları net değildir. Farklı revizyon tekniklerinde başarısızlık oranlarını bildiren çalışmalar Tablo 3'te gösterilmiştir.

\section{SONUÇ}

Omuz instabilitesinin cerrahi tedavisi sonrasında revizyon intiyacı \%15'e kadar çıkabilmektedir. Revizyon ihtiyacını doğuran nedenlerden en önde geleni ise nüks instabilitedir ve etiyolojisinde tekrarlayan travma, yetersiz rehabilitasyon ve teknik veya tanısal hatalar bulunmaktadır. Revizyon seçenekleri; revizyon artroskopik veya açık onarım, humerus tarafının rekonstrüksiyonu (örn., remplisaj) ve açık veya artroskopik anterior kemik blok prosedürlerini içerir. Uygun tedavi yöntemi ise bireyselleştirilmiş bir biçimde, hastada bulunan mevcut risk etkenleri, hastanın tıbbi geçmişi ve ihtiyaçları dikkate alınarak tasarlanmalıdır (Tablo 4).

\section{KAYNAKLAR}

1. Calvo E, Rodriguez-Vaquero G, Haeni D. Shoulder Instability Repair: Why It Fails. In: Milano G, Grasso A, Calvo A, Brzska R (eds). Management of Failed Shoulder Surgery. Berlin, Springer Verlag; 2018. p: 3-13. Crossref
2. Huber H, Gerber C. Voluntary subluxation of the shoulder in children. A long-term follow-up study of 36 shoulders. J Bone Joint Surg Br 1994;76(1):118-22. Crossref

3. Zabinski SJ, Callaway GH, Cohen S, Warren RF. Revision shoulder stabilization: 2- to 10-year results. J Shoulder Elbow Surg 1999;8(1):58-65. Crossref

4. Johansson K. Multidirectional instability of the glenohumeral joint: an unstable classification resulting in uncertain evidence-based practice. Br J Sports Med 2016;50(18):1105-6. Crossref

5. Sachs RA, Williams B, Stone ML, Paxton L, Kuney M. Open Bankart repair: correlation of results with postoperative subscapularis function. Am J Sports Med 2005;33(10):1458-62. Crossref

6. Probyn LJ, White LM, Salonen DC, Tomlinson G, Boynton EL. Recurrent symptoms after shoulder instability repair: direct MR arthrographic assessment--correlation with second-look surgical evaluation. Radiology 2007;245(3):814-23. Crossref

7. Ahmed I, Ashton F, Robinson CM. Arthroscopic Bankart repair and capsular shift for recurrent anterior shoulder instability: functional outcomes and identification of risk factors for recurrence. J Bone Joint Surg Am 2012;94(14):1308-15. Crossref

8. Voos JE, Livermore RW, Feeley BT, Altchek DW, Williams RJ, Warren RF, et al. Prospective evaluation of arthroscopic Bankart repairs for anterior instability. Am J Sports Med 2010;38(2):302-7. Crossref 
9. Wasserstein D, Dwyer T, Veillette C, Gandhi R, Chahal J, Mahomed N, Ogilvie-Harriset D. Predictors of dislocation and revision after shoulder stabilization in Ontario, Canada, from 2003 to 2008. Am J Sports Med 2013;41(9):2034-40. Crossref

10. Kim SH, Park JC, Park JS, Oh I. Painful jerk test: a predictor of success in nonoperative treatment of posteroinferior instability of the shoulder. Am J Sports Med 2004;32(8):1849-55. Crossref

11. Randelli P, Ragone V, Carminati S, Cabitza P. Risk factors for recurrence after Bankart repair a systematic review. Knee Surg Sports Traumatol Arthrosc 2012;20(11):2129-38. Crossref

12. Marquardt B, Garmann S, Schulte T, Witt KA, Steinbeck J, Pötzl W. Outcome after failed traumatic anterior shoulder instability repair with and without surgical revision. J Shoulder Elbow Surg 2007;16(6):742-7. Crossref

13. Cho NS, Hwang JC, Rhee YG. Arthroscopic stabilization in anterior shoulder instability: collision athletes versus noncollision athletes. Arthroscopy 2006;22(9):947-53. Crossref

14. Rhee YG, Ha JH, Cho NS. Anterior shoulder stabilization in collision athletes: arthroscopic versus open Bankart repair. Am J Sports Med 2006;34(6):979-85. Crossref

15. Balg F, Boileau P. The instability severity index score. A simple pre-operative score to select patients for arthroscopic or open shoulder stabilisation. J Bone Joint Surg Br 2007;89(11):14707. Crossref

16. Bühler M, Gerber C. Shoulder instability related to epileptic seizures. J Shoulder Elbow Surg 2002;11(4):339-44. Crossref

17. Thangarajah T, Lambert S. The management of recurrent shoulder instability in patients with epilepsy: a 15-year experience. J Shoulder Elbow Surg 2015;24(11):1723-7. Crossref

18. Rowe CR, Zarins B, Ciullo JV. Recurrent anterior dislocation of the shoulder after surgical repair. Apparent causes of failure and treatment. J Bone Joint Surg Am 1984;66(2):159-68. Crossref

19. Meehan RE, Petersen SA. Results and factors affecting outcome of revision surgery for shoulder instability. J Shoulder Elbow Surg 2005;14(1):31-7. Crossref

20. Tauber M, Resch H, Forstner R, Raffl M, Schauer J. Reasons for failure after surgical repair of anterior shoulder instability. $J$ Shoulder Elbow Surg 2004;13(3):279-85. Crossref

21. Porcellini G, Campi F, Pegreffi F, Castagna A, Paladini P. Predisposing factors for recurrent shoulder dislocation after arthroscopic treatment. J Bone Joint Surg Am 2009;91(11):2537-42. Crossref

22. Savoie FH 3rd, Holt MS, Field LD, Ramsey JR. Arthroscopic management of posterior instability: evolution of technique and results. Arthroscopy 2008;24(4):389-96. Crossref

23. Kim SH, Ha KI, Kim YM. Arthroscopic revision Bankart repair: a prospective outcome study. Arthroscopy 2002;18(5):469-82. Crossref

24. Boileau P, Villalba M, Héry JY, Balg F, Ahrens P, Neyton L. Risk factors for recurrence of shoulder instability after arthroscopic Bankart repair. J Bone Joint Surg Am 2006;88(8):1755-63. Crossref
25. An VV, Sivakumar BS, Phan K, Trantalis J. A systematic review and meta-analysis of clinical and patient-reported outcomes following two procedures for recurrent traumatic anterior instability of the shoulder: Latarjet procedure vs. Bankart repair. J Shoulder Elbow Surg 2016;25(5):853-63. Crossref

26. Thal R. Knotless suture anchor: arthroscopic bankart repair without tying knots. Clin Orthop Relat Res 2001;(390):42-51. Crossref

27. Cho NS, Lubis AM, Ha JH, Rhee YG. Clinical results of arthroscopic bankart repair with knot-tying and knotless suture anchors. Arthroscopy 2006;22(12):1276-82. Crossref

28. Bigliani LU, Kelkar R, Flatow EL, Pollock RG, Mow VC. Glenohumeral stability. Biomechanical properties of passive and active stabilizers. Clin Orthop Relat Res 1996;(330):13-30. Crossref

29. Shibata H, Gotoh M, Mitsui Y, Kai Y, Nakamura H, Kanazawa T, et al. Risk factors for shoulder re-dislocation after arthroscopic Bankart repair. J Orthop Surg Res 2014;9:53. Crossref

30. Calvo E, Granizo JJ, Fernández-Yruegas D. Criteria for arthroscopic treatment of anterior instability of the shoulder: a prospective study. J Bone Joint Surg Br 2005;87(5):677-83. Crossref

31. Yamamoto N, Itoi E, Abe H, Minagawa H, Seki N, Shimada Y, et al. Contact between the glenoid and the humeral head in abduction, external rotation, and horizontal extension: a new concept of glenoid track. J Shoulder Elbow Surg 2007;16(5):649-56. Crossref

32. Griffith JF, Antonio GE, Tong CW, Ming CK. Anterior shoulder dislocation: quantification of glenoid bone loss with CT. AJR Am J Roentgenol 2003;180(5):1423-30. Crossref

33. Di Giacomo G, Itoi E, Burkhart SS. Evolving concept of bipolar bone loss and the Hill-Sachs lesion: from "engaging/non-engaging" lesion to "on-track/off-track" lesion. Arthroscopy 2014;30(1):90-8. Crossref

34. Anderl W, Kriegleder B, Heuberer PR. All-arthroscopic implant-free iliac crest bone grafting: new technique and case report. Arthroscopy 2012;28(1):131-7. Crossref

35. Young DC, Rockwood CA Jr. Complications of a failed Bristow procedure and their management. J Bone Joint Surg Am 1991;73(7):969-81. Crossref

36. Cuéllar A, Cuéllar R, de Heredia PB. Arthroscopic revision surgery for failure of open Latarjet technique. Arthroscopy 2017;33(5):910-7. Crossref

37. Boileau P, Richou J, Lisai A, Chuinard C, Bicknell RT. The role of arthroscopy in revision of failed open anterior stabilization of the shoulder. Arthroscopy 2009;25(10):1075-84. Crossref

38. Locher J, Wilken F, Beitzel K, Buchmann S, Longo UG, Denaro $V$, et al. Hill-Sachs off-track lesions as risk factor for recurrence of instability after arthroscopic Bankart repair. Arthroscopy 2016;32(10):1993-9. Crossref

39. Yildirim K, Beyzadeoglu T. Arthroscopic assisted percutaneous screw fixation of a postage stamp anterior glenoid fracture. Acta Chir Orthop Traumatol Cech 2021;88(6): 456-60. 
40. Verweij LPE, van Spanning SH, Grillo A, Kerkhoffs GMMJ, Priester-Vink S, van Deurzen DFP, et al. Age, participation in competitive sports, bony lesions, ALPSA lesions, $>1$ preoperative dislocations, surgical delay and ISIS score $>3$ are risk factors for recurrence following arthroscopic Bankart repair: a systematic review and meta-analysis of 4584 shoulders. Knee Surg Sports Traumatol Arthrosc 2021;29(12):4004-14. Crossref

41. Waterman BR, Leroux T, Frank RM, Romeo AA. The evaluation and management of the failed primary arthroscopic Bankart repair. J Am Acad Orthop Surg 2020;28(15):607-16. Crossref

42. Arce G, Arcuri F, Ferro D, Pereira E. Is selective arthroscopic revision beneficial for treating recurrent anterior shoulder instability?. Clin Orthop Relat Res 2012;470(4):965-71. Crossref

43. McCabe MP, Weinberg D, Field LD, O'Brien MJ, Hobgood ER, Savoie FH 3rd. Primary versus revision arthroscopic reconstruction with remplissage for shoulder instability with moderate bone loss. Arthroscopy 2014;30(4):444-50. Crossref

44. Bartl C, Schumann K, Paul J, Vogt S, Imhoff AB. Arthroscopic capsulolabral revision repair for recurrent anterior shoulder instability. Am J Sports Med 2011;39(3):511-8. Crossref

45. Hiemstra LA, Sasyniuk TM, Mohtadi NG, Fick GH. Shoulder strength after open versus arthroscopic stabilization. Am J Sports Med 2008;36(5):861-87. Crossref

46. Arciero RA, Mazzocca AD. Mini-open repair technique of HAGL (humeral avulsion of the glenohumeral ligament) lesion. Arthroscopy 2005;21(9):1152. Crossref

47. Bhatia DN, DeBeer JF, van Rooyen KS. The "subscapularis-sparing" approach: a new mini-open technique to repair a humeral avulsion of the glenohumeral ligament lesion. Arthroscopy 2009;25(6):686-90. Crossref

48. Neviaser AS, Benke MT, Neviaser RJ. Open Bankart repair for revision of failed prior stabilization: outcome analysis at a mean of more than 10 years. J Shoulder Elbow Surg 2015;24(6):897-901. Crossref

49. Cho NS, Yi JW, Lee BG, Rhee YG. Revision open Bankart surgery after arthroscopic repair for traumatic anterior shoulder instability. Am J Sports Med 2009;37(11):2158-64. Crossref

50. Sisto DJ. Revision of failed arthroscopic bankart repairs. Am J Sports Med 2007;35(4):537-41. Crossref

51. Burkhart SS, De Beer JF, Barth JR, Cresswell T, Roberts C, Richards DP. Results of modified Latarjet reconstruction in patients with anteroinferior instability and significant bone loss [published correction appears in Arthroscopy. 2007 Dec;23(12):A16. Criswell, Tim [corrected to Cresswell,Tim]]. Arthroscopy 2007;23(10):1033-41. Crossref

52. Dumont GD, Vopat BG, Parada S, Cohn R, Makani A, Sanchez $G$, et al. Traditional versus congruent arc latarjet technique: effect on surface area for union and bone width surrounding screws. Arthroscopy 2017;33(5):946-52. Crossref

53. Silber JS, Anderson DG, Daffner SD, Brislin BT, Leland JM, Hilibrand AS, et al. Donor site morbidity after anterior iliac crest bone harvest for single-level anterior cervical discectomy and fusion. Spine (Phila Pa 1976) 2003;28(2):134-9. Crossref
54. Griesser MJ, Harris JD, McCoy BW, Hussain WM, Jones MJ, Bishop JY, et al. Complications and re-operations after Bristow-Latarjet shoulder stabilization: a systematic review. J Shoulder Elbow Surg 2013;22(2):286-92. Crossref

55. Di Giacomo G, de Gasperis N, Costantini A, De Vita A, Beccaglia MA, Pouliart N. Does the presence of glenoid bone loss influence coracoid bone graft osteolysis after the Latarjet procedure? A computed tomography scan study in 2 groups of patients with and without glenoid bone loss. J Shoulder Elbow Surg 2014;23(4):514-8. Crossref

56. Provencher MT, Ghodadra N, LeClere L, Solomon DJ, Romeo AA. Anatomic osteochondral glenoid reconstruction for recurrent glenohumeral instability with glenoid deficiency using a distal tibia allograft. Arthroscopy 2009;25(4):446-52. Crossref

57. Giannakos A, Vezeridis PS, Schwartz DG, Jany R, Lafosse L. All-arthroscopic revision Eden-Hybinette procedure for failed instability surgery: technique and preliminary results. Arthroscopy 2017;33(1):39-48. Crossref

58. Buza JA 3rd, lyengar JJ, Anakwenze OA, Ahmad CS, Levine WN. Arthroscopic Hill-Sachs remplissage: a systematic review. J Bone Joint Surg Am 2014;96(7):549-55. Crossref

59. Creighton RA, Romeo AA, Brown FM Jr, Hayden JK, Verma NN. Revision arthroscopic shoulder instability repair. Arthroscopy 2007;23(7):703-9. Crossref

60. Patel RV, Apostle K, Leith JM, Regan WD. Revision arthroscopic capsulolabral reconstruction for recurrent instability of the shoulder. J Bone Joint Surg Br 2008;90(11):1462-7. Crossref

61. Franceschi F, Longo UG, Ruzzini L, Rizzello G, Maffulli N, Denaro V. Arthroscopic salvage of failed arthroscopic Bankart repair: a prospective study with a minimum follow-up of 4 years. Am J Sports Med 2008;36(7):1330-6. Crossref

62. Barnes CJ, Getelman MH, Snyder SJ. Results of arthroscopic revision anterior shoulder reconstruction. Am J Sports Med 2009;37(4):715-9. Crossref

63. Krueger D, Kraus N, Pauly S, Chen J, Scheibel M. Subjective and objective outcome after revision arthroscopic stabilization for recurrent anterior instability versus initial shoulder stabilization. Am J Sports Med 2011;39(1):71-7. Crossref

64. Neri BR, Tuckman DV, Bravman JT, Yim D, Sahajpal DT, Rokito AS. Arthroscopic revision of Bankart repair. J Shoulder Elbow Surg 2007;16(4):419-24. Crossref

65. Schmid SL, Farshad M, Catanzaro S, Gerber C. The Latarjet procedure for the treatment of recurrence of anterior instability of the shoulder after operative repair: a retrospective case series of forty-nine consecutive patients. J Bone Joint Surg Am 2012;94(11):e75. Crossref

66. Bonnevialle $\mathrm{N}$, Ibnoulkhatib $\mathrm{A}$, Mansat $\mathrm{P}$, Rongières $\mathrm{M}$, Mansat $M$, Bonnevialle $P$. Outcomes of two surgical revision techniques for recurrent anterior shoulder instability following selective capsular repair. Orthop Traumatol Surg Res 2013;99(4):45563. Crossref

67. Flinkkilä T, Sirniö K. Open Latarjet procedure for failed arthroscopic Bankart repair. Orthop Traumatol Surg Res 2015;101(1):35-8. Crossref 